\title{
MERCADOTECNIA CON CAUSA EN TIEMPOS DE CORONAVIRUS
}

MARKETING CAUSED IN TIMES OF CORONAVIRUS

Mónica Álvarez-García ${ }^{1}$ * (D); Carlos Guerrero-Ibarra ${ }^{2}$ (D); Margarita Larios-Calva ${ }^{3}$ (D).

1.Universidad Tecnológica de Nezahualcóyotl.gmonica34@yahoo.com.mx

2. Universidad Tecnológica de Nezahualcóyotl.cgi_67@yahoo.com.mx,

3. Universidad Tecnológica de Nezahualcóyotl.marlarios_99@yahoo.com

*Autor de Correspondencia: Mónica Álvarez-García, correo electrónico:gmonica34@yahoo.com.mx

\section{RESUMEN}

El presente documento es el resultado del análisis de una revisión documental y cibergráfica dividida en dos partes, la primera para revisar los conceptos de mercadotecnia, mercadotecnia social y mercadotecnia con causa, la segunda consistió en revisar en las diferentes redes sociales a las empresas que aplicaron estrategias de mercadotecnia con causa en la pandemia por COVID-19 durante el periodo de abril 2020 a marzo de 2021 para entender como éstas, a través de sus actividades ayudaron a la sociedad y sector gubernamental para hacer frente a esta situación, pero sobre todo en el sector salud. Estas empresas lograron crear alianzas con organizaciones sin fines de lucro para mejorar su imagen y lealtad al igual que el de sus productos o servicios, esperando ser vistas como empresas socialmente responsables que ayudaron a la comunidad a la vez que se beneficiaron en el incremento de sus ventas.

Palabras clave: Mercadotecnia; mercadotecnia con causa; COVID-19.

Cómo citar:

Álvarez-García, Mónica; Guerrero-Ibarra, Carlos; Larios-Calva, Margarita. (2021). MERCADOTECNIA CON CAUSA EN TIEMPOS DE CORONAVIRUS. Revista de Investigaciones Universidad del Quindio, 33(S1), 96-112. https://doi.org/10.33975/riuq. vol33nS1.486 


\begin{abstract}
This document is the result of the analysis of a documentary and cybergraphic review divided into two parts, the first to review the concepts of marketing, social marketing and marketing with a cause, the second consisted of reviewing the companies that applied Marketing strategies with a cause in the COVID-19 pandemic during the period from April 2020 to March 2021 to understand how these, through their activities, helped society and the government sector to face this situation, but especially in the health sector. These companies managed to create alliances with non-profit organizations to improve their image and loyalty as well as that of their products or services, hoping to be seen as socially responsible companies that helped the community while benefiting from increasing their sales.
\end{abstract}

Keywords: Marketing; marketing with a cause; COVID-19.

\title{
INTRODUCCIÓN
}

La pandemia del COVID-19 que afectó a la humanidad desde el año pasado, ha sacado a flote la parte social y el compromiso que muchas empresas tienen para la sociedad. La devastadora situación, que ha provocado crisis económica, también ha dañado el tejido social y ha afectado a muchas familias, no sólo en México, sino en todo el mundo.

La mercadotecnia siempre ha sido una herramienta utilizada por las empresas para hacer llegar sus productos y servicios al consumidor final y satisfacer sus necesidades.

Ante la pandemia surgida en México por el COVID19 desde marzo del 2020, muchas empresas se han visto afectadas en sus ventas y para hacer frente a esta situación han tenido que implementar diversas estrategias de mercadotecnia, dando un giro al uso del marketing digital.

Diversas compañías como las que ofrecen equipo de cómputo y electrónicos, la industria de la ropa y el calzado, productos de cuidado personal, alimentos y bebidas; y por otro lado las cadenas de detallistas ante la imposibilidad de poder tener a la venta sus productos por las restricciones y políticas gubernamentales decidieron utilizar estrategias de e-commerce, ventas a través de los market place o redes sociales para hacer llegar sus productos a los consumidores que se encuentran en confinamiento para evitar los contagios.

Otras empresas voltearon a mirar al desarrollo de estrategias de mercadotecnia social, muchas de ellas apoyando con campañas para educar y concientizar al consumidor a seguir las medidas sanitarias y evitar la propagación del virus SARS-COV-2 a la vez que ponían a la venta sus productos y servicios.

Por otra parte diversas empresas implementaron estrategias de mercadotecnia con causa para mejorar su imagen apoyando a instituciones de gobierno, hospitales y servicios de seguridad y salud pública ofreciendo donaciones de cubrebocas, sanitizantes, uniformes, oxigeno, equipo médico, mejorando las instalaciones hospitalarias, renovando la infraestructura, construyendo y reconstruyendo hospitales.

La presente investigación muestra como algunas empresas pusieron en práctica estrategias de mercadotecnia con causa y se mostraron empáticos con sus empleados, el entorno y en general con 
la sociedad aportando recursos materiales y apoyo a los que en ese momento lo requerían para seguir adelante.

La crisis sanitaria obligó a algunas compañías que sus marcas, además de ser reconocidas por sus productos o servicios, pudieran generar en la gente un impacto importante, si muestran su lado social y apoyan en el momento de crisis.

\section{MARCO TEÓRICO}

Para entender que es el marketing con causa primero es necesario definir que es el Marketing, Kotler lo define como el proceso social y administrativo por el cual los grupos e individuos satisfacen sus necesidades al crear e intercambiar bienes y servicios, Kotler (2013).

Las empresas han invertido demasiado dinero en desarrollar estrategias que ayuden a vender sus productos y servicios para satisfacer las necesidades de los consumidores, sin embargo, en la actualidad, el nuevo enfoque es buscar otros medios que no solo sean la publicidad o la promoción de ventas, sino buscando hacer labores sociales y actividades sustentables que ayuden al medio ambiente y a la sociedad. De ahí que han surgido nuevos enfoques como lo son; el marketing social y el marketing con causa o mercadotecnia con causa.

El concepto de marketing social sostiene que la estrategia de marketing debería entregar valor a los clientes de manera que mantenga o mejore el bienestar tanto de los consumidores y los negocios y que, a la vez, conserve o mejore la capacidad de las generaciones futuras para satisfacer sus necesidades. (Kotler 2013).

De acuerdo con Biglione y Woods (en Giuliani 2012), la agencia de marketing relacionado con causas sociales más conocida de los Estados Unidos, Cone Inc., presentó un concepto amplio en el que dice que el marketing relacionado con causas sociales es "un poderoso posicionamiento utilizado para fortalecer el valor de la marca y para potenciar la imagen corporativa, con un significativo resultado e impacto en la sociedad".

Por su parte Pringle y Thompson (en Giuliani 2012) dice que se "puede entender como una herramienta estratégica del marketing y del posicionamiento que asocia a una empresa o marca con una cuestión o causa socialmente relevante, para beneficio mutuo".

Marconi (en Ramos y Silva 2003) denomina de Cause Marketing "La acción en la cual una empresa, una organización no lucrativa o entidad similar, gestionan una imagen, un producto, un servicio o un mensaje para beneficio mutuo".

Gilliani (2012) afirma "que las acciones de marketing relacionadas con causas sociales hacen posible no solo el aumento de la notoriedad o la mejora de la imagen corporativa, sino también el aumento de la posibilidad de generar nuevos negocios lo que, por consecuencia, tiende a resultar en el aumento de las ganancias a largo plazo".

Lo cierto es que, la mercadotecnia con causa está totalmente ligada a la responsabilidad social de las empresas, la cual se define como el "compromiso con la humanidad en general y una forma de rendición de cuentas de su desempeño basado en la apropiación y en el uso de recursos que originalmente no le 
pertenecen" (Alonso, López y Castrucci, 2006, p.176).

La responsabilidad social según Carroll (en Mozas Moral 2010) “implica la realización de un negocio de manera que sea económicamente rentable, respetuoso de la ley, ético y socialmente solidario" y tiene 4 dimensiones, como se muestra en la siguiente imagen.

\section{Pirámide de responsabilidades sociales}

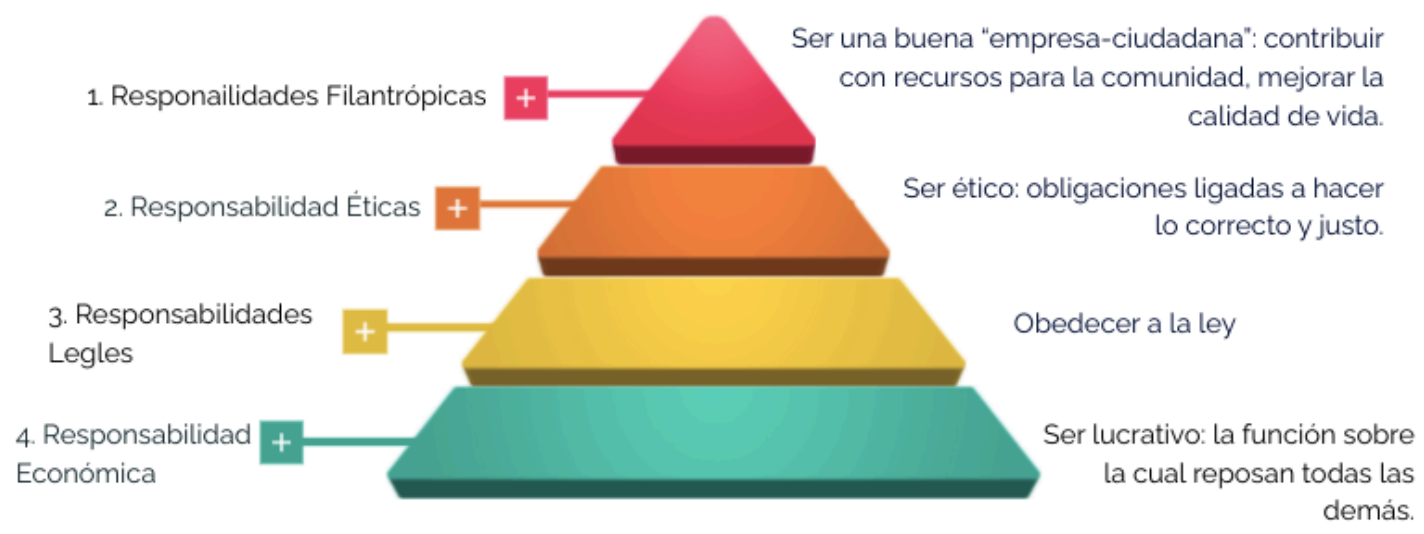

Figura 1. Pirámide de responsabilidades sociales

Fuente: Giulliani (2012)

La responsabilidad social, les da a las empresas una nueva imagen, la cual le envía un mensaje a sus clientes o consumidores, diciéndoles que están comprometidas con la sociedad, con una causa, con el planeta; dependiendo el tipo "de producto" que promuevan.

En el marketing con causa, la empresa relaciona el programa de marketing con una obra de beneficencia para generar buena voluntad, una causa sin fines de lucro y una empresa lucrativa se basa en la idea de que los consumidores son más propensos a comprar productos de compañías que están dispuestas a colaborar a una buena causa.

Los clientes perciben que hay pocas diferencias notables entre los productos y las empresas que los venden. Muchos profesionales usan el marketing con causa para desarrollar lazos más fuertes con la marca y generar en los consumidores, así como en las empresas lealtad a la marca. Clow K.E. (2010).

La mercadotecnia con causa es una actividad comercial en la cual empresas y organizaciones sin fines de lucro forman alianzas para comercializar una imagen, un producto o servicio, en busca de un beneficio común. Cuando una compañía implementa adecuadamente un proyecto de esta naturaleza, puede obtener grandes beneficios: desde ayudar en el desarrollo de su comunidad, hasta fortalecer su imagen corporativa, influir positivamente en la decisión de compra de sus consumidores e impulsar el ejercicio colectivo de la responsabilidad social. Fechac $(\mathrm{S} / \mathrm{F})$

Sin duda para que las empresas pongan en práctica la mercadotecnia con causa deben unirse a una causa común para generar imagen, incrementar sus ventas y poder donar parte de sus utilidades para esa causa. La empresa apoya sin fines de lucro, solo busca ayudar a la sociedad, de esta forma los beneficios son mutuos. 
Algunos de los beneficios para las organizaciones pueden ser:

1. Crecimiento de la lealtad de sus clientes

2. Obtener nuevos clientes

3. Mejorar la imagen de la empresa, marca, productos o servicios

4. Cumplimiento de las expectativas de los clientes

5. El crecimiento en un corto plazo de las ventas.

Anteriormente las empresas hacían donativos a causas sociales sin pensar mucho en el impacto o beneficio de dichas aportaciones. Por lo anterior, se daba por hecho estos esfuerzos filantrópicos por parte de las grandes empresas. En la actualidad, la mayoría de las empresas quieren saber con precisión cuál será el beneficio que obtendrán. Aunque los líderes de las empresas crean que una obra benéfica vale la pena, el apoyo a dicha obra debe producir, de algún modo, un beneficio tangible.

De lo contrario, la empresa no debe brindar apoyo. Los posibles beneficios incluyen:

- Clientes adicionales.

- Aumento de las utilidades.

- Buena voluntad de los consumidores en el futuro.

- Mejores relaciones con las dependencias gubernamentales.

- Menos opiniones públicas negativas. Clow K.E. (2010).

El marketing con causa también es importante para las organizaciones sin fines de lucro. La competencia ha aumentado tanto en el mundo empresarial como en el de las entidades no lucrativas. Un número creciente de éstas compiten por aportaciones y donativos. Las relaciones estratégicas con las empresas pueden aumentar de manera considerable las contribuciones a las organizaciones no lucrativas.

Estas relaciones con empresas no sólo redundan en aumentos directos de los ingresos, sino en mayor publicidad para la organización sin fines de lucro. Clow K.E. (2010).

\section{Características de la mercadotecnia con causa (MCC)}

Ramos e Silva (2003), en su artículo "Delimitación del Marketing con Causa o Marketing Social Corporativo, mediante el análisis de empresas que realizan acciones de responsabilidad social" presenta un mapa en donde establece las características de la mercadotecnia con causa, en donde presenta claramente cinco dimensiones de la MCC. La primera se refiere a la forma de compromiso de la empresa con la sociedad y, puede presentarse como actos de filantropía, patrocino, promoción, y todas las formas de apoyo que les puede brindar a sus Stakeholders.

La segunda dimensión representa al sector (mercado meta) al que va destinada la MCC, puede ser desde una población normal (jóvenes), hasta grupos vulnerables (personas con capacidades diferentes).

La tercera dimensión se orienta al objetivo o eje (idea que se pretende "vender") a la sociedad. La cuarta dimensión al tipo de cliente y la quinta, al tipo de servicio o producto que se puede ofertar. 


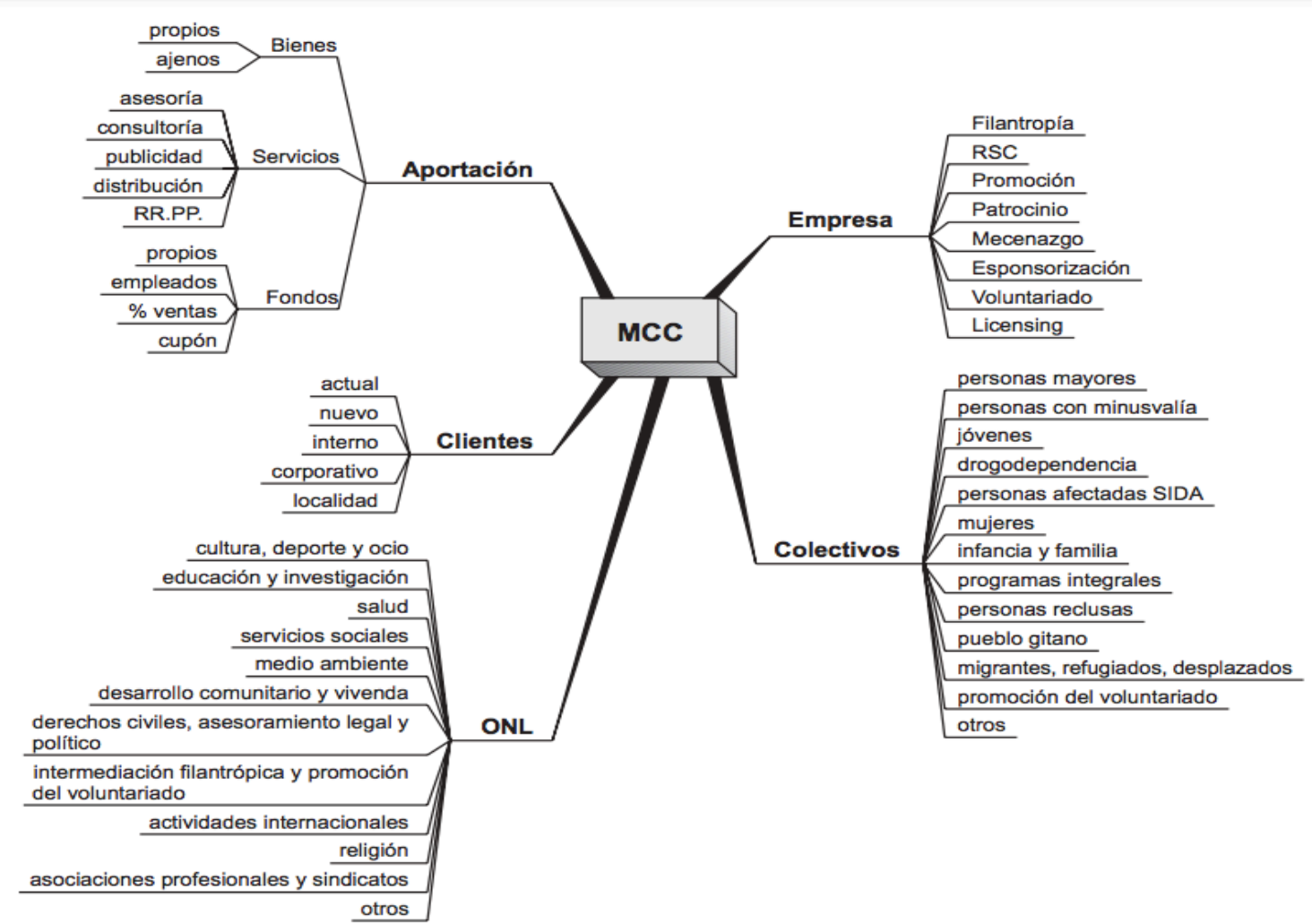

Figura 2. Características de la MCC Fuente: Ramos E. Silva, 2003

\section{Para que la mercadotecnia con causa resulte estratégica la empresa debe entre otras cosas:}

1. Identificar un tema o causa relacionada con el servicio o producto de la compañía, su mercado y la comunidad que la rodea: identificar claramente a los consumidores clave para conocer qué causa apoyarían, analizar las necesidades de la comunidad para establecer cuáles son las más importantes, y relacionarlas con aquellas detectadas como prioritarias tanto para la empresa como para los consumidores.

2. Buscar socios: consultar qué organizaciones trabajan para solucionar el problema elegido como prioritario, con el fin de generar alianzas con ellas e involucrar a aquellos proveedores con los que se tiene relación, con el fin de sumarlos al esfuerzo.

3. Alinear objetivos: Definir un periodo de tiempo para la implementación del proyecto, determinar los recursos (económicos y/o en especie) que se destinarán a la causa seleccionada y determinar el mecanismo a través del cual se recaudarán y aplicarán dichos recursos (porcentaje de las ventas de uno o varios productos o servicios, venta neta de un producto o servicio, donativo fijo a la institución independientemente del desempeño de las ventas, desarrollo de eventos alternos, etc.)

4. Desarrollar un plan de trabajo: determinar cuáles son las actividades que seguir y quienes, dentro y fuera de la empresa, serán responsables de ejecutarlas y hacer partícipe del plan de trabajo a todos los colaboradores de la empresa ya que en la medida en que se les involucre, el impacto en la mente del consumidor aumenta y la lealtad de la fuerza laboral se fortalece.

5. Comunicar y evaluar el programa continuamente: definir, en conjunto con la institución beneficiaria, los indicadores de impacto del proyecto, determinar qué instrumentos se utilizarán para comunicar a la comunidad los apoyos que brinda la empresa gracias a la preferencia de sus consumidores (televisión abierta, radio, para buses, impresos, etc.) y determinar qué instrumentos se utilizarán 
para comunicar a los empleados los logros que se han obtenido gracias al esfuerzo de cada uno de ellos (boletines internos, reuniones periódicas, reconocimientos, etc.) Fechac (S/F)

\section{Diferencias entre mercadotecnia social y con causa}

La mercadotecnia social surgida en 1970, está dirigida a vender actitudes y comportamientos, con el fin de cambiar un comportamiento o postura a nivel social. Se enfoca en lo que la sociedad quiere o necesita, en lugar de tratar de persuadirlos para que realicen una compra.

Por otro lado, la mercadotecnia con causa, es en la que una empresa adopta una causa social de alguna Organización no gubernamental (ONG) y hacen en conjunto una estrategia de Marketing social (Moliner, en Ramos e Silva 2003)

A continuación, se presentan las diferencias entre ambas.

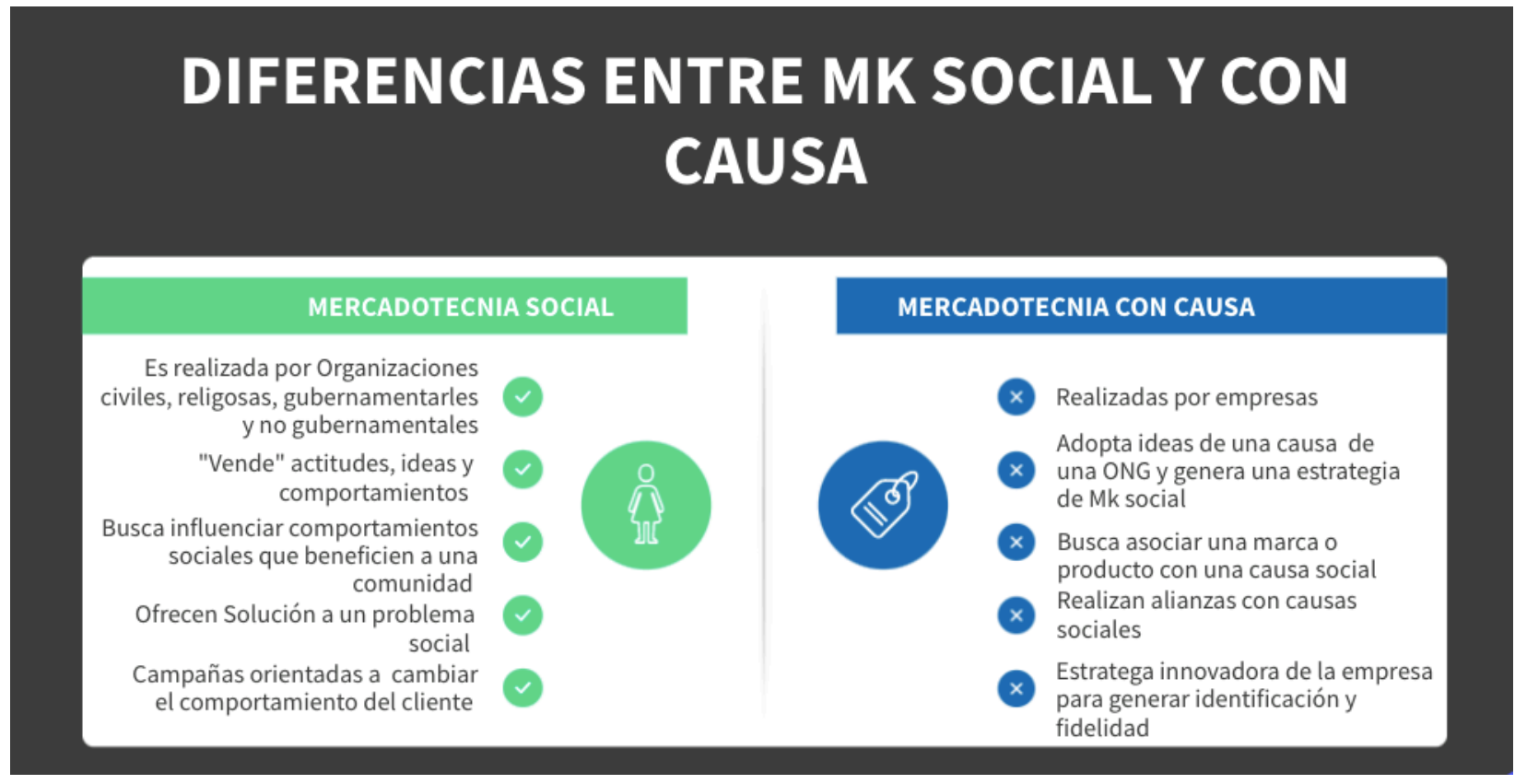

Figura 3. Diferencia entre Marketing social y con causa

Fuente: Elaboración propia

Finalmente es necesario hacer hincapié del porqué las empresas deben participar con inversiones para apoyar a la sociedad cuando existen problemas que atañen a la comunidad como la situación en la que se encuentra el país originado por la pandemia por el COVID-19.

\section{¿Por qué los esfuerzos de marketing son importantes en épocas de crisis?.}

Visto como estrategia, cuando se trata de un problema social, como se está viviendo actualmente la pandemia por COVID-19, el aplicar la mercadotecnia con causa, se vuelve una necesidad para lograr un posicionamiento por parte de las empresas para aprovechar el momento y vender sus productos o servicios. Que si lo analizamos, son pocas las empresas que verdaderamente se han involucrado a brindar apoyo a la sociedad.

Según una investigación realizada por el Grupo Kantar en marzo de 2020, más del 80\% de los 
entrevistados coinciden en que las marcas deben comunicarse con los consumidores con el objetivo de enfrentar la crisis de salud pública. Por lo tanto, los consumidores esperan una comunicación que atienda las necesidades de la población o sociedad, por eso, no se recomienda que las empresas ignoren lo que está sucediendo.

En la misma investigación, el 21\% de los entrevistados expresaron que las marcas tienen la capacidad de guiar los cambios necesarios, sirviendo como ejemplo. Este dato muestra que diversos consumidores ven las marcas como agentes de transformación del ambiente. Es importante notar que esta crisis también es una oportunidad para que las marcas se fortalezcan en la mente de sus consumidores, ocupando un lugar de respeto y fidelidad. En ese sentido, los esfuerzos de marketing son importantes en épocas de crisis, pues comunican el posicionamiento de la empresa con respecto a lo que está sucediendo, al mismo tiempo que se relacionan de forma directa y personal con el público objetivo, fortaleciendo la credibilidad del negocio. Sales Force Latinoamérica (2020).

¿Qué hacer con respecto a la marca y las campañas en medio de la crisis?

Pocas son las marcas que han mostrado estar preparadas para enfrentar una crisis como la de COVID-19. Lamentablemente, es común que las empresas no sepan cómo promover sus marcas y diseñar campañas en este momento. Sin embargo, es necesario crear una estrategia humanitaria y centrada en la salud de la población durante este período. Obviamente, vender es muy importante para cualquier empresa, pero enfocarse en las ventas no puede ser prioridad ahora, sobre todo con respecto a las grandes corporaciones. Sales Force Latinoamérica (2020).

Por esta razón es importante que las empresas estén dispuestas a ayudar, no solo a lucrar y se involucren para brindar apoyo a la sociedad o sector salud que en estos momentos dado que la infraestructura del sector salud es insuficiente y existe una gran cantidad de personas que han sido contagiadas.

\section{MÉTODO}

\section{Objetivo}

Analizar las estrategias de mercadotecnia con causa realizadas por empresas en México, durante el periodo de abril de 2020 a marzo de 2021 para lograr generar imagen, involucrar al consumidor, apoyar a la sociedad mexicana y el sector de salud pública.

\section{Tipo de Investigación}

Para realizar este proyecto se utilizó la investigación exploratoria, en la primera parte se realizó una investigación de carácter documental y en internet para incluir los principales conceptos de: mercadotecnia, mercadotecnia social y mercadotecnia con causa, sus beneficios e importancia. Cabe mencionar que el objetivo de la mercadotecnia social se llega a confundir, pero sin embargo se realizan estrategias muy diferentes en su aplicación.

La segunda fase refiere una búsqueda en las redes sociales como Facebook de diferentes empresas que, con motivo de la pandemia del Coronavirus que aqueja actualmente al mundo, se comprometieron con la sociedad y Organizaciones Gubernamentales y se manifestaron como empresas socialmente responsables, al utilizar la mercadotecnia con causa para apoyar a la sociedad, posteriormente se realizó un cuadro comparativo para describir las diferentes actividades, las organizaciones a las que apoyaron y en qué consistieron sus apoyos. 
Se pretende demostrar que estas empresas implementaron una estrategia de marketing con causa, difundiendo sus actividades a través de medios digitales que les permitieron vincular con la población y lograr el reconocimiento de su marca o producto.

El análisis se hizo con 35 empresas de diferentes sectores y tamaños, para evidenciar las estrategias de mercadotecnia con causa realizadas durante la pandemia, desde abril de 2020 a febrero de 2021.

\section{HALLAZGOS}

En este apartado se presentan los resultados de la investigación realizada en medios documentales e internet.

Algunas de las empresas que han utilizado marketing con causa durante la pandemia son: PFIZER, INFRA, PISA, ASTRA ZENECA, ARCO Y MARATHON PETROLEUM, FUNDACIÓN GRUPO MÉXICO, GRUPO MODELO, MEDIGAS, TENARIS TAMSA, FARMAPIEL, EL PALACIO DE HIERRO, EMPRESA BIC, GINGROUP, AXA MÉXICO, MARS MÉXICO, La marca EMPERADOR en colaboración con PEPSICO, EMPRESA DE TECNOLOGÍA OPPO, TELEFÓNICA MOVISTAR, DOW, THE HOME DEPOT, FUNDACIÓN CARLOS SLIM, FUNDACIÓN TELMEX, TELCEL y FUNDACIÓN INBURSA, ELITE, entre otras.

La siguiente tabla es una lista de empresas, que desde el inicio y durante de la pandemia, han estado apoyando a la población a través de estrategias de marketing con causa; el cual en su mayoría fue a través de medios digitales.

\begin{tabular}{|c|c|c|c|c|c|}
\hline FECHA & EMPRESA & $\begin{array}{c}\text { COLECTIVO } \\
\text { (BENEFICIADOS) }\end{array}$ & $\begin{array}{l}\text { ORGANIZACIÓN } \\
\text { NO LUCRATIVA } \\
\text { BENEFICIADA } \\
\end{array}$ & TIPO DE APOYO & MONTO \\
\hline $\begin{array}{l}\text { Abril } \\
2020\end{array}$ & Tenaris Tamsa & Personal de salud & $\begin{array}{c}\text { Delegación del IMSS } \\
\text { Veracruz Norte y al Hospital } \\
\text { de Alta Especialidad de } \\
\text { Veracruz }\end{array}$ & $\begin{array}{l}\text { Materiales y equipo } \\
\text { médico como } \\
\text { ventiladores, overoles } \\
\text { y mascarillas } \\
\text { quirúrgicas. }\end{array}$ & $\begin{array}{l}\text { No se } \\
\text { menciona }\end{array}$ \\
\hline $\begin{array}{l}\text { Abril } \\
2020\end{array}$ & Medigas & $\begin{array}{c}\text { Pacientes } \\
\text { diagnosticados con } \\
\text { Covid-19 } \\
\end{array}$ & $\begin{array}{l}\text { Hospital Comunitario Covid } \\
\text { de Nova }\end{array}$ & $\begin{array}{l}50 \text { tanques de } \\
\text { oxígeno. }\end{array}$ & $\begin{array}{c}\text { No se } \\
\text { menciona }\end{array}$ \\
\hline $\begin{array}{l}\text { Abril } \\
2020\end{array}$ & Grupo Infra ${ }^{\circledR}$ & $\begin{array}{c}\text { Pacientes } \\
\text { diagnosticados con } \\
\text { Covid-19 }\end{array}$ & SEDENA & $\begin{array}{l}13 \text { cápsulas de } \\
\text { aislamiento para } \\
\text { traslado de pacientes } \\
\text { infecto-contagiosos y } \\
\text { más de } 800 \text { filtros. }\end{array}$ & $\begin{array}{c}\text { No se } \\
\text { menciona }\end{array}$ \\
\hline $\begin{array}{l}\text { Abril } \\
2020\end{array}$ & Grupo Infra ${ }^{\circledR}$ & $\begin{array}{c}\text { Pacientes } \\
\text { diagnosticados con } \\
\text { Covid-19 }\end{array}$ & $\begin{array}{l}\text { Hospital General Regional } \\
\text { No. } 66 \text { del IMSS en Ciudad } \\
\text { Juárez, Chihuahua. }\end{array}$ & $\begin{array}{c}\text { Inversión en } \\
\text { optimizar } \\
\text { instalaciones de } \\
\text { oxígeno medicinal. }\end{array}$ & $\begin{array}{c}\text { No se } \\
\text { menciona }\end{array}$ \\
\hline $\begin{array}{l}\text { Abril } \\
2020\end{array}$ & Grupo Infra ${ }^{\circledR}$ & $\begin{array}{l}\text { Pacientes } \\
\text { diagnosticados con } \\
\text { Covid-19 }\end{array}$ & $\begin{array}{l}\text { Unidad Temporal de } \\
\text { COVID19 en el Centro } \\
\text { Citibanamex }\end{array}$ & $\begin{array}{l}\text { Instalación de una } \\
\text { red de oxígeno } \\
\text { compuesta por } 35 \text { mil } \\
\text { galones de } \mathrm{O} 2 \text { y } 11 \\
\text { mil metros de tubería }\end{array}$ & $\begin{array}{c}\text { No se } \\
\text { menciona }\end{array}$ \\
\hline
\end{tabular}




\begin{tabular}{|c|c|c|c|c|c|}
\hline $\begin{array}{l}\text { Abril } \\
2020\end{array}$ & Grupo Infra ${ }^{\circledR}$ & $\begin{array}{c}\text { Pacientes } \\
\text { diagnosticados con } \\
\text { Covid-19 }\end{array}$ & $\begin{array}{c}\text { Hospital General de Zona No. } \\
1 \text { del IMSS en Durango. } \\
\text { Hospital Civil de Morelia, } \\
\text { Michoacán } \\
\text { Hospital de la Mujer en } \\
\text { Fresnillo, Zacatecas. } \\
\text { Hospital General de Ciudad } \\
\text { Obregón, Sonora }\end{array}$ & $\begin{array}{c}\text { Inversión en } \\
\text { optimizar } \\
\text { instalaciones de } \\
\text { oxígeno medicinal }\end{array}$ & \\
\hline $\begin{array}{l}\text { Abril } \\
2020\end{array}$ & $\begin{array}{c}\text { Grupo Infra }{ }^{\circledR} \\
\text { Corporación } \\
\text { Interamericana } \\
\text { de } \\
\text { Entretenimiento } \\
\text { (CIE) }\end{array}$ & $\begin{array}{c}\text { Pacientes } \\
\text { diagnosticados con } \\
\text { Covid-19 }\end{array}$ & $\begin{array}{l}\text { Hospital de Expansión para } \\
\text { pacientes COVID-19 en } \\
\text { el Autódromo Hermanos } \\
\text { Rodríguez }\end{array}$ & $\begin{array}{c}\text { Se instaló } 2 \text { tanques } \\
\text { termo con capacidad } \\
\text { combinada de } \\
7,500 \text { galones y } 5 \\
\text { kilómetros de tubería } \\
\text { para suministrar } \\
\text { oxígeno a } 192 \text { camas } \\
\text { hospitalarias y } 26 \text { de } \\
\text { cuidados intensivos. }\end{array}$ & $\begin{array}{c}\text { No se } \\
\text { menciona }\end{array}$ \\
\hline $\begin{array}{l}\text { Mayo } \\
2020\end{array}$ & Grupo Infra ${ }^{\circledR}$ & $\begin{array}{c}\text { Pacientes } \\
\text { diagnosticados con } \\
\text { Covid-19 }\end{array}$ & $\begin{array}{l}\text { Hospital General de Ciudad } \\
\text { Obregón, Sonora } \\
\text { Hospital General Regional } \\
\text { No. } 12 \text { del IMSS “Lic. Benito } \\
\text { Juárez” en Mérida, Yucatán. } \\
\text { Hospital General de } \\
\text { Valladolid en Mérida, Yucatán } \\
\text { Hospital Regional de Alta } \\
\text { Especialidad en Oaxaca. } \\
\text { Hospital General Regional } \\
\text { No. } 180 \text { del IMSS en } \\
\text { Guadalajara, Jalisco } \\
\text { Hospital General de Zona } \\
\text { 1 del IMSS en Saltillo, } \\
\text { Coahuila. } \\
\text { Hospital General Jesús } \\
\text { Kumate Rodríguez en } \\
\text { Cancún, Quintana Roo } \\
\text { Hospital General de Zona } \\
1 \text { del IMSS en Tapachula, } \\
\text { Chiapas. } \\
\text { Hospital General Chilapa en } \\
\text { Guerrero } \\
\text { Hospital General Chilapa en } \\
\text { Guerrero. } \\
\text { Hospital General Chilapa en } \\
\text { Guerrero } \\
\text { Hospital General de Zona } 53 \\
\text { del IMSS en Los Reyes la } \\
\text { Paz, Estado de México. } \\
\text { Hospital General Regional } \\
\text { 72 del IMSS en Tlalnepantla, } \\
\text { Estado de México }\end{array}$ & $\begin{array}{c}\text { Inversión en } \\
\text { optimizar } \\
\text { instalaciones de } \\
\text { oxígeno medicinal }\end{array}$ & $\begin{array}{c}\text { No se } \\
\text { menciona }\end{array}$ \\
\hline
\end{tabular}




\begin{tabular}{|c|c|c|c|c|c|}
\hline $\begin{array}{l}\text { Mayo } \\
2020\end{array}$ & $\begin{array}{c}\text { Fundación } \\
\text { Carlos Slim } \\
\text { Telmex } \\
\text { Inbursa } \\
\text { Walmart } \\
\text { Bimbo } \\
\text { Alfredo Harp } \\
\text { Helu. } \\
\text { CityBanamex } \\
\text { Coopel } \\
\text { Femsa } \\
\text { CocaCola } \\
\text { Fundación } \\
\text { Infra } \\
\text { Codere } \\
\text { Sertull } \\
\text { Barcel } \\
\text { HSBC } \\
\text { Takeda }\end{array}$ & $\begin{array}{c}\text { Pacientes } \\
\text { diagnosticados con } \\
\text { Covid-19 }\end{array}$ & $\begin{array}{c}\text { Unidad Temporal COVID19, } \\
\text { Centro City Banamex }\end{array}$ & $\begin{array}{l}\text { Reconversión de la } \\
\text { Sala "D" en Sala de } \\
\text { Terapia Intensiva con } \\
\text { un incremento de } 22 \\
\text { camas alcanzando un } \\
\text { total de } 54 . \\
\text { Tomógrafo de } 16 \\
\text { cortes que ayudará } \\
\text { a la precisión en el } \\
\text { diagnóstico } \\
\text { Equipamiento } \\
\text { de monitores y } \\
\text { ventiladores para } 18 \\
\text { camas post-terapia } \\
\text { intensiva } \\
\text { Incremento de } 40 \text { a } \\
80 \text { camas con Puntas } \\
\text { Nasales de Alto Flujo } \\
\text { Incremento de } 102 \\
\text { camas hospitalarias } \\
\text { con oxígeno }\end{array}$ & $\begin{array}{l}\text { No se } \\
\text { menciona }\end{array}$ \\
\hline $\begin{array}{l}\text { Mayo } \\
2020\end{array}$ & $\begin{array}{c}\text { Grupo Infra }{ }^{\circledR} \\
\text { CEMEX } \\
\text { COMEX } \\
\text { HILTI } \\
\text { CONSTRUHUB }\end{array}$ & $\begin{array}{c}\text { Pacientes } \\
\text { diagnosticados con } \\
\text { Covid-19 }\end{array}$ & Diversos hospitales & $\begin{array}{c}6 \text { módulos } \\
\text { hospitalarios en } \\
\text { diversas regiones del } \\
\text { país con } 280 \text { camas } \\
\text { adicionales para la } \\
\text { atención de pacientes } \\
\text { con COVID-19. }\end{array}$ & $\begin{array}{l}\text { No se } \\
\text { menciona }\end{array}$ \\
\hline $\begin{array}{l}\text { Mayo } \\
2020\end{array}$ & Grupo Infra ${ }^{\circledR}$ & $\begin{array}{c}\text { Pacientes } \\
\text { diagnosticados con } \\
\text { Covid-19 }\end{array}$ & $\begin{array}{c}\text { Hospital General de Zona } \\
29 \text { del IMSS en San Juan } \\
\text { Aragón, CDMX. }\end{array}$ & $\begin{array}{c}\text { Inversión en } \\
\text { optimizar } \\
\text { instalaciones de } \\
\text { oxígeno medicinal }\end{array}$ & $\begin{array}{l}\text { No se } \\
\text { menciona }\end{array}$ \\
\hline $\begin{array}{l}\text { Mayo } \\
2020\end{array}$ & $\begin{array}{c}\text { PiSA } \\
\text { Farmacéutica }\end{array}$ & $\begin{array}{c}\text { Pacientes } \\
\text { diagnosticados con } \\
\text { Covid-19 }\end{array}$ & Jalisco & $\begin{array}{l}\text { Donó un total de } 200 \\
\text { mil kits de protección } \\
\text { que contienen careta, } \\
\text { cubrebocas y guantes } \\
\text { para el sector salud, } \\
\text { así como alrededor } \\
\text { de } 2.2 \text { millones de } \\
\text { sueros rehidratantes } \\
\text { Electrolit. medicinal }\end{array}$ & $\begin{array}{l}\text { No se } \\
\text { menciona }\end{array}$ \\
\hline $\begin{array}{l}\text { Mayo } \\
2020\end{array}$ & AstraZeneca & Personal de salud & $\begin{array}{c}\text { Instituto Mexicano del Seguro } \\
\text { Social }\end{array}$ & $\begin{array}{c}\text { Donó } 350 \text { mil } \\
\text { mascarillas } \\
\text { quirúrgicas }\end{array}$ & $\begin{array}{l}\text { No se } \\
\text { menciona }\end{array}$ \\
\hline $\begin{array}{l}\text { Mayo } \\
2020\end{array}$ & Grupo Modelo & $\begin{array}{c}\text { Personal de } \\
\text { salud y Pacientes } \\
\text { diagnosticados con } \\
\text { Covid-19 }\end{array}$ & $\begin{array}{c}\text { Secretaría de Movilidad } \\
\text { de la Ciudad de México } \\
\text { (SEMOVI). }\end{array}$ & $\begin{array}{l}\text { Donó } 10 \text { mil cubre } \\
\text { bocas }\end{array}$ & $\begin{array}{l}\text { No se } \\
\text { menciona }\end{array}$ \\
\hline
\end{tabular}




\begin{tabular}{|c|c|c|c|c|c|}
\hline $\begin{array}{l}\text { Mayo } \\
2020\end{array}$ & Farmapiel & $\begin{array}{c}\text { Personal de } \\
\text { salud y Pacientes } \\
\text { diagnosticados con } \\
\text { Covid-19 }\end{array}$ & $\begin{array}{l}\text { Hospital Infantil de México } \\
\text { Federico Gómez, El Instituto } \\
\text { Nacional de Ciencias y } \\
\text { Nutrición Salvador Zubirán, } \\
\text { El Hospital General de } \\
\text { México Dr. Manuel Gea } \\
\text { González, Servicios Urbanos } \\
\text { de la CDMX. En el Estado } \\
\text { de Aguascalientes, ISSSTE } \\
\text { Hospital General, IMSS } \\
\text { Hospitales Generales de Zona } \\
1,2 \text { y } 3 \text { y Centenario Hospital } \\
\text { Hidalgo, entre otros. }\end{array}$ & $\begin{array}{l}\text { Donó } 15 \text { toneladas de } \\
\text { gel sanitizante Purity. }\end{array}$ & $\begin{array}{l}\text { No se } \\
\text { menciona }\end{array}$ \\
\hline $\begin{array}{l}\text { Mayo } \\
2020\end{array}$ & $\begin{array}{l}\text { El Palacio de } \\
\text { Hierro }\end{array}$ & Personal de salud & $\begin{array}{c}\text { Instituto Mexicano del Seguro } \\
\text { Social }\end{array}$ & $\begin{array}{c}\text { Donó } 12,700 \\
\text { insumos médicos } \\
\text { como: cubrebocas, } \\
\text { guantes, gafas y batas } \\
\text { quirúrgicas y } 200 \\
\text { litros de gel anti- } \\
\text { bacterial. }\end{array}$ & $\begin{array}{l}\text { No se } \\
\text { menciona }\end{array}$ \\
\hline $\begin{array}{l}\text { Mayo } \\
2020\end{array}$ & Empresa BIC & Personal de salud & $\begin{array}{c}\text { Instituto Mexicano del Seguro } \\
\text { Social }\end{array}$ & $\begin{array}{l}\text { Donó } 2.4 \text { millones } \\
\text { de instrumentos } \\
\text { de escritura, } \\
\text { encendedores y } \\
\text { rastrillos }\end{array}$ & $\begin{array}{l}\text { Más de } \$ 36 \\
\text { millones de } \\
\text { pesos }(\$ 1.5 \mathrm{M} \\
\text { USD) en } \\
\text { producto }\end{array}$ \\
\hline $\begin{array}{l}\text { Mayo } \\
2020\end{array}$ & GIN Group & Personal de salud & $\begin{array}{c}\text { Instituto Nacional de } \\
\text { Enfermedades Respiratorias } \\
\text { (INER) }\end{array}$ & $\begin{array}{c}\text { Donó 2,500 } \\
\text { uniformes quirúrgicos }\end{array}$ & $\begin{array}{l}\text { No se } \\
\text { menciona }\end{array}$ \\
\hline $\begin{array}{l}\text { Mayo } \\
2020\end{array}$ & AXA México & Personal de salud & $\begin{array}{c}\text { Hospitales de IMSS Bienestar } \\
\text { ubicados en las ciudades de } \\
\text { Tijuana, Tuxtla Gutiérrez, } \\
\text { Tapachula, Monterrey y } \\
\text { Oaxaca. }\end{array}$ & $\begin{array}{l}\text { Dos ventiladores } \\
\text { mecánicos para } \\
\text { bebés, } 100 \text { monitores } \\
\text { de signos vitales, } \\
3,000 \text { cajas de } \\
\text { guantes, y } 1,000 \text { cajas } \\
\text { de toallas desechables }\end{array}$ & $\begin{array}{c}\$ 13.8 \\
\text { millones de } \\
\text { pesos (mdp), }\end{array}$ \\
\hline $\begin{array}{l}\text { Mayo } \\
2020\end{array}$ & AXA México & Personal de salud & $\begin{array}{l}\text { Instituto Nacional de } \\
\text { Ciencias Médicas y Nutrición } \\
\text { "Salvador Zubirán”. }\end{array}$ & $\begin{array}{c}\text { Donativo de } \\
\text { cubrebocas, } \\
\text { respiradores N95, } \\
\text { goggles, caretas, } \\
\text { contenedores para el } \\
\text { manejo de residuos, } \\
\text { cubre zapatos, batas } \\
\text { desechables y guantes }\end{array}$ & $\begin{array}{l}\text { Valor de } \$ 1.7 \\
\text { millones de } \\
\text { pesos }\end{array}$ \\
\hline $\begin{array}{l}\text { Mayo } \\
2020\end{array}$ & Mars México & Población general & $\begin{array}{l}\text { Comunidades y sectores } \\
\text { vulnerables del país }\end{array}$ & $\begin{array}{c}\text { Donativo de } \\
\text { cubrebocas, } \\
\text { respiradores N95, } \\
\text { goggles, caretas, } \\
\text { contenedores para el } \\
\text { manejo de residuos, } \\
\text { cubre zapatos, batas } \\
\text { desechables y guantes }\end{array}$ & $\begin{array}{l}25 \text { millones } \\
\text { de pesos en } \\
\text { donación de } \\
\text { productos y } \\
\text { efectivo }\end{array}$ \\
\hline
\end{tabular}


Revista de Investigaciones - Universidad del Quindío

\begin{tabular}{|c|c|c|c|c|c|}
\hline $\begin{array}{l}\text { Mayo } \\
2020\end{array}$ & $\begin{array}{l}\text { Mars México, } \\
\text { a través de } \\
\text { AMANC }\end{array}$ & Personal de salud & $\begin{array}{l}\text { Comunidades y sectores } \\
\text { vulnerables del país }\end{array}$ & $\begin{array}{c}\text { Insumos de } \\
\text { protección médica }\end{array}$ & $\begin{array}{c}\text { Donó \$1.5 } \\
\text { millones de } \\
\text { pesos }\end{array}$ \\
\hline $\begin{array}{l}\text { Mayo } \\
2020\end{array}$ & $\begin{array}{c}\text { Emperador } \\
\text { Con apoyo de } \\
\text { la fundación } \\
\text { PepsiCo México }\end{array}$ & Personal de salud & Hospitales del IMSS & $\begin{array}{c}\text { Donó } 20 \text { mil } \\
\text { cubrebocas N95 }\end{array}$ & $\begin{array}{l}\text { No se } \\
\text { menciona }\end{array}$ \\
\hline $\begin{array}{l}\text { Mayo } \\
2020 \\
\end{array}$ & OPPO & Personal de salud & Cruz Roja Mexicana & Donó cubrebocas & $\begin{array}{c}\text { No se } \\
\text { menciona }\end{array}$ \\
\hline $\begin{array}{l}\text { Mayo } \\
2020\end{array}$ & $\begin{array}{l}\text { Telefónica } \\
\text { Movistar }\end{array}$ & Personal de salud & Fundación IMSS A.C & $\begin{array}{l}\text { Insumos de } \\
\text { protección personal }\end{array}$ & $\$ 11.3$ mdp \\
\hline $\begin{array}{l}\text { Mayo } \\
2020\end{array}$ & $\begin{array}{l}\text { Telefónica } \\
\text { Movistar }\end{array}$ & Personal de salud & $\begin{array}{l}\text { Hospital General de México } \\
\text { Dr. Eduardo Liceaga, al } \\
\text { Instituto Nacional de Ciencias } \\
\text { Médicas y Nutrición Salvador } \\
\text { Zubirán, y al Hospital Infantil } \\
\text { de México Federico Gómez. }\end{array}$ & $\begin{array}{c}\text { Insumos de } \\
\text { protección personal }\end{array}$ & $\begin{array}{l}\text { No se } \\
\text { menciona }\end{array}$ \\
\hline $\begin{array}{l}\text { Junio } \\
2020\end{array}$ & Dow & Personal de salud & $\begin{array}{c}\text { Fundación IMSS y Fundación } \\
\text { ISSSTE }\end{array}$ & $\begin{array}{l}25,000 \text { batas de } \\
\text { aislamiento }\end{array}$ & $\begin{array}{l}\text { No se } \\
\text { menciona }\end{array}$ \\
\hline $\begin{array}{l}\text { Junio } \\
2020\end{array}$ & $\begin{array}{l}\text { The Home } \\
\text { Depot }\end{array}$ & Personal de salud & $\begin{array}{c}\text { Instituto Mexicano del } \\
\text { Seguro Social, la Cruz } \\
\text { Roja Mexicana, el Sistema } \\
\text { Nacional para el Desarrollo } \\
\text { Integral de la Familia (DIF), } \\
\text { el Hospital General de } \\
\text { México, el Hospital Materno } \\
\text { Infantil A.C., el Hospital } \\
\text { del Sureste en Tabasco, } \\
\text { el Hospital Regional de } \\
\text { Coatzacoalcos y la Clínica de } \\
\text { Medicina Familiar Sinaloa, } \\
\text { entre otros. }\end{array}$ & Mascarillas y goggles & $\begin{array}{l}\text { \$2.1 millones } \\
\text { de pesos }\end{array}$ \\
\hline $\begin{array}{l}\text { Junio } \\
2020\end{array}$ & $\begin{array}{l}\text { Fundación } \\
\text { Carlos Slim, } \\
\text { Fundación } \\
\text { TELMEX Telcel } \\
\text { y Fundación } \\
\text { Inbursa }\end{array}$ & Personal de salud & 30 hospitales de México & $\begin{array}{c}\text { Equipo Médico, } \\
\text { equipos médicos } \\
\text { y de diagnóstico, } \\
\text { Ventiladores, } \\
1 \text { Equipo de } \\
\text { Ultrasonido,5 } \\
\text { Equipos para análisis } \\
\text { de pruebas de } \\
\text { COVID-19, 2,842 } \\
\text { Oxímetros, } 1,885 \\
\text { Medicamentos, } \\
\text { 103,777 insumos } \\
\text { para aplicación de } \\
\text { pruebas. }\end{array}$ & $\begin{array}{l}\text { Donación } \\
\text { de } \$ 1,000 \\
\text { millones de } \\
\text { pesos }\end{array}$ \\
\hline $\begin{array}{l}\text { Junio } \\
2020\end{array}$ & Grupo Infra ${ }^{\circledR}$ & $\begin{array}{c}\text { Pacientes } \\
\text { diagnosticados con } \\
\text { Covid-19 }\end{array}$ & $\begin{array}{l}\text { Hospital Naval de Mazatán, } \\
\text { Sinaloa }\end{array}$ & $\begin{array}{c}\text { Inversión en } \\
\text { optimizar } \\
\text { instalaciones de } \\
\text { oxígeno medicinal }\end{array}$ & $\begin{array}{l}\text { No se } \\
\text { menciona }\end{array}$ \\
\hline
\end{tabular}




\begin{tabular}{|c|c|c|c|c|c|}
\hline $\begin{array}{l}\text { Junio } \\
2020\end{array}$ & Grupo Infra ${ }^{\circledR}$ & $\begin{array}{c}\text { Pacientes } \\
\text { diagnosticados con } \\
\text { Covid-19 }\end{array}$ & $\begin{array}{c}\text { Hospital Naval de Mazatán, } \\
\text { Sinaloa }\end{array}$ & $\begin{array}{l}7 \text { módulos de } \\
\text { evaluación y } \\
\text { clasificación de } \\
\text { pacientes }\end{array}$ & $\begin{array}{l}\text { No se } \\
\text { menciona }\end{array}$ \\
\hline $\begin{array}{l}\text { Junio } \\
2020\end{array}$ & Grupo Infra ${ }^{\circledR}$ & $\begin{array}{c}\text { Pacientes } \\
\text { diagnosticados con } \\
\text { Covid-19 }\end{array}$ & Hospital Central Militar & $\begin{array}{l}\text { Tanque de oxígeno } \\
\text { medicinal, } 10 \\
\text { cápsulas para } \\
\text { traslado de pacientes } \\
\text { infectocontagiosos y } \\
\text { más de } 600 \text { filtros }\end{array}$ & $\begin{array}{l}\text { No se } \\
\text { menciona }\end{array}$ \\
\hline $\begin{array}{l}\text { Junio } \\
2020\end{array}$ & Empresa Elite & $\begin{array}{c}\text { Pacientes } \\
\text { diagnosticados con } \\
\text { Covid-19 }\end{array}$ & Gobierno de Tamaulipas & $\begin{array}{c}500 \text { mil unidades } \\
\text { de mascarillas tipo } \\
\text { quirúrgicas }\end{array}$ & $\begin{array}{l}\text { No se } \\
\text { menciona }\end{array}$ \\
\hline Julio 2020 & Grupo Infra ${ }^{\circledR}$ & $\begin{array}{c}\text { Pacientes } \\
\text { diagnosticados con } \\
\text { Covid-19 }\end{array}$ & $\begin{array}{c}\text { Patrimonio de la Beneficencia } \\
\text { Pública }\end{array}$ & $\begin{array}{c}25,000 \\
\text { mascarillas N95 } \\
\text { infectocontagiosos y } \\
\text { más de } 600 \text { filtros }\end{array}$ & $\begin{array}{l}\text { No se } \\
\text { menciona }\end{array}$ \\
\hline Julio 2020 & Grupo Infra ${ }^{\circledR}$ & $\begin{array}{c}\text { Pacientes } \\
\text { diagnosticados con } \\
\text { Covid-19 }\end{array}$ & Fundación IMSS & $\begin{array}{l}50 \text { ventiladores } \\
\text { pulmonares }\end{array}$ & $\begin{array}{l}\text { No se } \\
\text { menciona }\end{array}$ \\
\hline $\begin{array}{l}\text { Agosto } \\
2020\end{array}$ & $\begin{array}{c}\text { Arco y } \\
\text { Marathon } \\
\text { Petroleum }\end{array}$ & Personal de salud & Hospitales de México & $\begin{array}{l}38,900 \text { piezas de } \\
\text { equipo de protección } \\
\text { persona }\end{array}$ & $\begin{array}{l}\text { No se } \\
\text { menciona }\end{array}$ \\
\hline $\begin{array}{l}\text { Agosto } \\
2020\end{array}$ & $\begin{array}{l}\text { Fundación } \\
\text { Grupo México }\end{array}$ & Personal de salud & $\begin{array}{l}\text { La Secretaría de Salud (SS) de } \\
\text { Coahuila. }\end{array}$ & $\begin{array}{l}\text { Siete ventiladores de } \\
\text { respiración asistida, } \\
\text { así como equipos de } \\
\text { protección personal } \\
\text { para ambulancias }\end{array}$ & $\begin{array}{l}\text { No se } \\
\text { menciona }\end{array}$ \\
\hline $\begin{array}{l}\text { Octubre } \\
2020\end{array}$ & Grupo Infra ${ }^{\circledR}$ & Personal de salud & $\begin{array}{l}\text { DIF de San Luis Potosí, } \\
\text { el cual fue recibido por la } \\
\text { Presidenta del DIF Estatal, } \\
\text { Sra. Lorena María Valle } \\
\text { Rodríguez }\end{array}$ & $\begin{array}{c}\text { Donativo de } 10,000 \\
\text { cubrebocas KN95 } \\
\text { y } 1,264 \text { cubrebocas } \\
\text { N95 }\end{array}$ & $\begin{array}{l}\text { No se } \\
\text { menciona }\end{array}$ \\
\hline $\begin{array}{l}\text { Diciembre } \\
2020\end{array}$ & Grupo Infra ${ }^{\circledR}$ & Personal de salud & $\begin{array}{l}\text { Industria farmacéutica y sus } \\
\text { operadores logísticos }\end{array}$ & $\begin{array}{c}\text { Suministro de N2 } \\
\text { líquido y CO2 } \\
\text { en pellet para la } \\
\text { transportación a } \\
\text { bajas temperaturas } \\
\text { de medicamentos y } \\
\text { vacunas }\end{array}$ & $\begin{array}{l}\text { No se } \\
\text { menciona }\end{array}$ \\
\hline $\begin{array}{l}\text { Diciembre } \\
2020\end{array}$ & Grupo Infra ${ }^{\circledR}$ & Personal de salud & $\begin{array}{c}\text { Instituto Mexicano del Seguro } \\
\text { Socia }\end{array}$ & $\begin{array}{l}\text { Donativo de } 100 \mathrm{mil} \\
\text { cubrebocas KN95 al }\end{array}$ & $\begin{array}{c}\text { No se } \\
\text { menciona }\end{array}$ \\
\hline
\end{tabular}




\begin{tabular}{|c|c|c|c|c|c|}
\hline $\begin{array}{c}\text { Enero } \\
2021\end{array}$ & Grupo Infra ${ }^{\circledR}$ & $\begin{array}{c}\text { Pacientes } \\
\text { diagnosticados con } \\
\text { Covid-19 }\end{array}$ & $\begin{array}{c}\text { Procuraduría Federal del } \\
\text { Consumidor (Profeco), la } \\
\text { Comisión Federal para la } \\
\text { protección contra riesgos } \\
\text { sanitarios (Cofepris) y otras } \\
\text { empresas productoras y } \\
\text { distribuidoras de oxígeno } \\
\text { medicinal }\end{array}$ & $\begin{array}{c}\text { La campaña } \\
\text { "Devuelve tu tanque. } \\
\text { Por amor a la vida". } \\
\text { Si ya no necesitas } \\
\text { el cilindro o } \\
\text { concentrador que } \\
\text { tienes en casa, } \\
\text { contáctanos para } \\
\text { programar su } \\
\text { recolección llamando } \\
\text { al } 55 \text { 5329 } 3068 \text { o } \\
\text { escríbenos al correo } \\
\text { atencionaclientes@ } \\
\text { infra.com.mx }\end{array}$ & $\begin{array}{l}\text { No se } \\
\text { menciona }\end{array}$ \\
\hline $\begin{array}{c}\text { Febrero } \\
2021\end{array}$ & $\begin{array}{c}\text { Grupo Radio } \\
\text { Centro. Joya } \\
93.7 \\
\text { Con apoyo de la } \\
\text { empresa Super } \\
\text { Medi-K }\end{array}$ & $\begin{array}{c}\text { Pacientes } \\
\text { diagnosticados con } \\
\text { Covid-19 }\end{array}$ & $\begin{array}{c}\text { Alcaldías: Iztapalapa, Gustavo } \\
\text { A. Madero y municipios como } \\
\text { Ecatepec y Naucalpan }\end{array}$ & $\begin{array}{c}\text { Campaña } \\
\text { “Oxigenando tu } \\
\text { vida". Regalando } \\
\text { recargas de oxigeno }\end{array}$ & $\begin{array}{l}\text { No se } \\
\text { menciona }\end{array}$ \\
\hline $\begin{array}{c}\text { Febrero } \\
2021\end{array}$ & Grupo Infra ${ }^{\circledR}$ & Personal de salud & $\begin{array}{c}\text { Instituto Mexicano del Seguro } \\
\text { Social } \\
\end{array}$ & $\begin{array}{c}\text { Donativo de } 150 \text { mil } \\
\text { mascarillas KN95 }\end{array}$ & $\begin{array}{l}\text { No se } \\
\text { menciona }\end{array}$ \\
\hline $\begin{array}{c}\text { Marzo } \\
2021\end{array}$ & Grupo Infra ${ }^{\circledR}$ & $\begin{array}{c}\text { Pacientes } \\
\text { diagnosticados con } \\
\text { Covid-19 }\end{array}$ & $\begin{array}{c}\text { Con Autoridades de la Ciudad } \\
\text { de México }\end{array}$ & $\begin{array}{l}\text { Recarga de cilindros } \\
\text { portátiles sin costo en } \\
\text { Sala de Armas de la } \\
\text { Magdalena Mixhuca } \\
\text { (puerta 7). }\end{array}$ & $\begin{array}{l}\text { No se } \\
\text { menciona }\end{array}$ \\
\hline $\begin{array}{c}\text { Marzo } \\
2021\end{array}$ & Grupo Infra ${ }^{\circledR}$ & $\begin{array}{c}\text { Pacientes } \\
\text { diagnosticados con } \\
\text { Covid-19 }\end{array}$ & $\begin{array}{c}\text { Con Autoridades de la Ciudad } \\
\text { de México }\end{array}$ & $\begin{array}{l}\text { Programar su } \\
\text { recolección de } \\
\text { cilindros. } \\
\text { "Contáctanos } \\
\text { llamando al } 800712 \\
2525 "\end{array}$ & $\begin{array}{l}\text { No se } \\
\text { menciona }\end{array}$ \\
\hline
\end{tabular}

\section{CONCLUSIONES}

Como resultado de la investigación se puede concluir que:

1. La Mercadotecnia con causa le permite a las empresas, crear vínculos con los consumidores, es una actividad comercial en la cual empresas y organizaciones sin fines de lucro forman alianzas para comercializar una imagen, un producto o servicio, en busca de un beneficio común, por un lado ayudar a la sociedad y por otro lado el incremento de sus ventas para la empresa además de: el aumento de la lealtad y expectativas de los consumidores, así como el número de estos mismos, sin olvidar generar o mejorar su imagen.

2. La MCC sensibiliza a las empresas, quienes además de ganar dinero con la iniciativa, crean lealtad para su marca o producto.

3. Una de las características importantes de la MCC son las alianzas y a través de la investigación, se notó que las empresas hicieron alianzas con fundaciones u organizaciones gubernamentales y no gubernamentales, para poder implementar su estrategia de marketing con causa.

4. Las empresas que utilizan este tipo de estrategias son consideradas por los usuarios como empresas socialmente responsables y tienen mayor aceptación. 
5. Las estrategias de las empresas: Pfizer, INFRA, PISA, ASTRA ZENECA, Arco y Marathon Petroleum, Fundación Grupo México, Grupo Modelo, Medigas, Tenaris Tamsa, Farmapiel Fundación Carlos Slim, Telmex, Inbursa. Walmart. Bimbo. Alfredo Harp Helu, CitiBanamex, Coopel. Femsa, CocaCola Fundación, Codere. Sertull. Barcel, HSBC. Takeda, Fundación Pepsico, Bic, Home Depot, Telefónica Dow, Movistar, Tenaris Tamsa, Mediga, Liverpool y otras más realizaron estrategias de mercadotecnia con causa relacionadas principalmente con la donación de cubrebocas, mascarillas, ventiladores, oxigeno, equipo y uniformes médicos, construcción de unidades de atención u hospitales del sector público como el IMSS, equipamiento de hospitales para beneficiar al sector salud y a los pacientes con COVID-19, debido a la carencia de infraestructura con la que cuenta este sector para atender a los pacientes con COVID-19. (Problemática principal detectada por las empresas).

6. Una de las empresas más activas en el periodo de la pandemia, fue Grupo Infra ${ }^{\circledR}$, la cual “cuenta con 30 empresas dedicadas a la producción, venta y distribución de gases criogénicos, industriales, de alta pureza, especiales, medicinales, así como tanques de almacenamiento criogénico, soldaduras, máquinas y equipos para soldar y cortar, equipo de protección personal, así como una amplia gama de productos relacionado (Roldan, 2021).

7. Así mismo, menciona que dicha empresa "sólo en 2020 obtuvieron mil 777 millones de pesos por vender oxígeno a 15 instituciones como el IMSS, ISSSTE, SEDENA, Secretaría de Salud, Hospitales de especialidad, el Instituto Nacional de Ciencias Médicas y Nutrición y hasta Laboratorios de Biológicos o Reactivos de México (BIRMEX), entre otros". Mismos a los que menciona en sus redes sociales, que hizo donaciones.

8. Otras empresas como Palacio de Hierro, no sólo mostraron su compromiso con la sociedad haciendo donaciones de materiales, también puso en "marcha el programa "Dignifica tu Vida IAP" que tiene como objetivo contribuir a reactivar la economía de 100 familias de las Alcaldías Tláhuac, Xochimilco y Milpa Alta a través de acciones que involucran la compra de despensas a pequeños productores y comerciantes para después donarlas a familias en situación vulnerable”. (Revista contacto, 2020)

9. Algunas de estas empresas utilizan esta estrategia, para apoyar la causa y para deducir impuestos, por lo cual dejan sentado el importe de su donación u aportación.

10. Los medios de comunicación utilizados (plaza) para la difusión de la estrategia, fueron medios digitales como redes sociales e internet.

11. La estrategia cumplió con tres factores para el éxito: 1) La causa era totalmente coherente con la problemática y percibida como un acto de responsabilidad social por parte de la sociedad. 2) La comunicación fue clara y llegó al público al que estaba dirigida; a través de los medios más usados durante la pandemia: redes sociales. 3) La estrategia se presentó a la población, de tal manera que se sintió el compromiso de la empresa y su aportación a la causa o problemática que en ese momento se estaba dando.

12. Para que las empresas logren obtener los beneficios esperados y recuperar su inversión al realizar las estrategias de mercadotecnia con causa deben tener presente: seleccionar adecuadamente las organizaciones con las que van a trabajan para solucionar el problema elegido, especificar el tiempo para la implementación del proyecto, determinar los recursos financieros y materiales que se estipularan a la causa seleccionada, definir los objetivos: y mecanismos a través del cual se recaudarán y aplicarán dichos recursos (porcentaje de las ventas) destinados a las actividades a realizar y quienes serán los participantes dentro y fuera de la empresa, difundir y evaluar el programa junto con las organizaciones con las que se está trabajando y determinar los medios de comunicar a la sociedad y los apoyos que se ofrecen a los consumidores a través de los medios difusión como: la televisión, radio, redes sociales, impresos, entre otros medios. 


\section{REFERENCIAS}

1. Citibanamex, extraído de https://www.centrocitibanamex.com/es/sumamos-por-mx/ (accessed marzo 18, 2021).

2. Clow K.E., (2010), Publicidad, promoción y comunicación integral en marketing, México, Ed. Prentice Hall.

3. Facebook, extraído de: https://www.facebook.com/grupoinframx/ (accessed febrero 24, 2021).

4. Fechac (S/F), Mercadotecnia con causa social, extraído de: http://www.fechac.org/pdf/ rse/mercadotecnia_con_causa_pasos_basicos.pdf (accessed febrero 26, 2021).

5. Instagram, extraído de: https://www.instagram.com/p/CK-EDK_LWSz/ (accessed febrero 24, 2021).

6. Kotler, P., \& Armstrong, G. (2013), Fundamentos de Marketing, México, Pearson Educacion.

7. Mars México. Mars México. enero 27, 2021. https://mex.mars.com/es-MX/noticias-historias/ articulos/donamos-25m-ante-covid-19?language_content_entity=es-MX (accessed marzo 13, 2021).

8. Mostar, Fundación Telefónica. Fundación Telefónica Mostar. mayo 26, 2020. https://valorcompartido.com/fundacion-telefonica-sumafuerzas-con-el-personal-sanitario/ (accessed marzo 13, 2021).

9. Mozas Moral, Adoración et all. (2010),"'LA RESPONSABILIDAD SOCIAL CORPORATIVA Y SU PARALELISMO CON LAS SOCIEDADES COOPERATIVAS ." REVESCO 13: 75-100.

10. Nayeli, Roldan. https://www.animalpolitico.com/2021/01/empresas-concentran-venta-oxigenofederacion/. Prod. Animal Político. México, enero 06, 2021. (accessed febrero 24, 2021).

11. PETROQUIMEX. PETROQUIMEX. abril 27, 2020. https://petroquimex.com/arco-realizaradonativos-de-equipo-de-proteccion-personal-a-los-trabajadores-de-la-salud/ (accessed marzo 13, 2021).

12. Porter, Michael, (2008), Ventaja competitiva. Mexico, Editorial Patria.

13. Ramos E. Silva, Joao A. (2003), "Delimitación del Marketing con Causa o Marketing Social Corporativo mediante el análisis de empresas que realizan acciones de responsabilidad social." Edited by Universidad del País Vasco. Cuadernos de Gestión, 65-82.

14. Revista contacto (2020), El Palacio de Hierro dona material y comida al personal médico. México, extraído de: https://revistacontacto.com.mx/el-palacio-de-hierro-dona-material-y-comida-alpersonal-medico/ (accessed marzo4, 2021).

15. Revista contacto. El Palacio de Hierro dona material y comida al personal médico. México, Mayo $15,2020$.

16. Rolda, N. (2021), Animal Político, México extraído de: https://www.animalpolitico.com/2021/01/ empresas-concentran-venta-oxigeno-federacion/ (accessed marzo4, 2021).

17. RTV, Agencia de noticias. Mas Noticias. Abril 10, 2020. http://www.masnoticias.mx/tamsa-donaequipo-de-proteccion-a-personal-de-salud/ (accessed marzo 13, 2021).

18. Sales Force Latinoamérica (2020), Marketing en Tiempos de Crisis, extraído de: https://www. salesforce.com/mx/blog/2020/04/marketing-en-tiempos-de-crisis.html (accessed marzo 8, 2021).

19. Valor Compartido. junio 8, 2020. https://valor-compartido.com/the-home-depot-supera-los-2mdp-en-donaciones-al-sector-salud/ (accessed marzo 13, 2021).

20. Valor Compartido. mayo 25, 2020. https://valor-compartido.com/tag/donacion/page/5/ (accessed marzo 13, 2021).

21. Valor compartido. Valor compartido. mayo 15, 2020. https://valor-compartido.com/gingroupdona-2500-uniformes-quirurgicos-al-iner/ (accessed marzo 13, 2021).

22. Valor compartido. Valor compartido. Mayo 15, 2020. https://valor-compartido.com/poderparaellosiniciativa-de-emperador-para-apoyar-al-sector-salud/ (accessed marzo 13, 2021).

23. Valor Compartido. Valor Compartido. mayo 27, 2020. https://valor-compartido.com/tag/donacion/ page/5/ (accessed marzo 13, 2021). 